Available Online : https://proceeding.researchsynergypress.com/index.php/cset/index

RSF Conference Series: Engineering and Technology

ISSN 2809-6843 (Online) | 2809-6878 (Print)

Volume 1 Number 1 (2021): 394-398

\title{
Earthquake Relocation Studies near Local Scale Sources using Double-Difference Technique
}

\author{
Wrego Seno Giamboro' ${ }^{1}$, Hafiz Hamdalah ${ }^{2}$ \\ 1,2 Geophysical Department FTM UPN “Veteran” Yogyakarta, Indonesia
}

\begin{abstract}
Determination of the location of the hypocenter is very necessary to monitor the potential for seismic hazard. Positioning and seismic energy can help safety workers determine which areas can be mined or temporarily halted. Earthquakes in underground mines are caused by seismic induction due to mining activities such as blasting processes, hydrofracturing, vehicle activities, etc. Earthquakes that occur are generally clustering. Earthquake events generally occur in mine openings, this is caused by mass compensation taken. The data used in this study are synthetic micro-earthquake data around the mining area. To obtain a high level of accuracy and precision, especially in determining the location and depth in determining the hypocenter using the Double-Difference (DD) method. The results of the microseismic relocation in the study area are well covered, as evidenced by the residual histogram and shift distribution. The shift of the microseismic before and after being relocated spread in all directions with the dominant direction in the NE - SW direction. The value of the microseismic shift before and after being relocated ranged from 0.5 meters to 150 meters
\end{abstract}

Keywords: Microseismic, Relocation, Geometry, Double - Difference

\section{INTRODUCTION}

This is an open access article under the CC-BY-NC license

This study will examine the first and main problem in seismological studies, namely the relocation of the hypocenter. For areas with high seismic intensity such as underground mining, an accurate hypocenter determination algorithm is needed, this is done because of the safety of workers and underground mining assets. The problem with the hypocenter relocation methods used today is that not much has been discussed about a clustered earthquake. Earthquake events that occur are generally scattered, therefore this study will discuss an algorithm for determining the hypocenter that can provide the right solution in the field of earthquake clustering so that it can mitigate seismic disasters in underground mines as early as possible. The purpose of this study was to obtain an accurate earthquake relocation near the source using the Double-difference Technique approach.

\section{LITERATURE REVIEW}

The main objective of applying seismic networks in mining is the continuous monitoring of seismicity in mining areas (Gibowicz and Lasocki 2001; Mendecki and Sciocatti 1997). Seismic monitoring generally consists of determining the location of the hypocenter, energy, and estimation of the seismic moment (Scales and Tenorio (2001); Hidayat et. al., 2020). To improve the accuracy and reliability of data analysis as well as the need to analyze very small seismic events on a local scale, many improvements are needed in seismic data analysis procedures. In this study, seismicity analysis will be carried out in underground mines which require a high level of accuracy and precision in determining the location of the hypocenter. Determining the location of the hypocenter in underground mines is necessary to minimize the potential for seismic hazards in underground mines (Ma, et al., 2020).

\section{RESEARCH METHOD}

The research method uses microseismic relocation with fortran language. The data used is synthetic data that has been made into a data catalog. The data consists of the date, time of the event, station, scale, depth and error or uncertainty of each of the parameters mentioned above. Synthetic data creation is done by analyzing existing real data, but for the sake of security and permission from the company, we cannot display the data. Synthetic data is made in such a way that it resembles real conditions. Synthetic data creation using Artificial Intelligence Computing Platform using python language.

Corresponding author:

wrego_seno@upnyk.ac.id

DOI: $10.31098 /$ cset.v1i1.406 
Double - Difference (DD) Method

The double-difference method assumes that if the distance between two adjacent earthquake sources is much smaller than the distance to the station, and has the same velocity heterogeneity, the wave rays from the two sources are considered to be almost the same (Waldhauser and Ellsworth, 2000). Figure 1 shows an illustration of two earthquake sources $i$ and $j$ which are close and relatively far from the recording sensors $k$ and $l$.

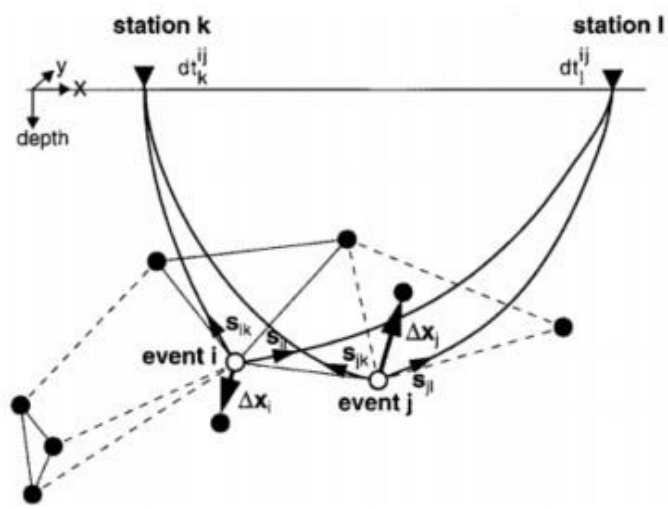

Figure 1. Illustration of the application of the double-difference method used to relocate earthquake hypocenters (Waldhauser and Ellsworth, 2000).

The arrival time of the T wave from an earthquake source i to an earthquake station is expressed by the wave ray theory,

$$
T^{i}=\tau^{i}+\int_{i}^{k} u d s
$$

where $\tau^{i}$ is the time of earthquake occurrence from source $i, u$ is the slowness vector, and $d s$ is the partition of the wave ray path. The relationship between arrival time and source location is very nonlinear, therefore linearization is carried out by calculating the misfit between the observed data and the predicted arrival time $r_{i}^{i}$

$$
r_{k}^{i}=\sum_{l=1}^{3} \underset{\partial x^{i}}{-}{ }_{k}^{i} \Delta x^{i}+\Delta \tau^{i}+\boldsymbol{J}^{k} \delta u d s
$$

Equation 2 is substituted with the event from source $\mathrm{j}$ received by station $\mathrm{k}$, then we get:

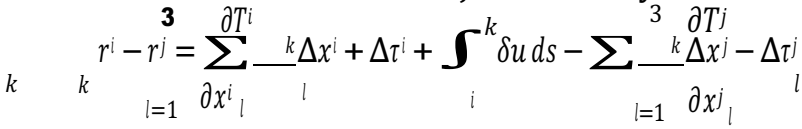

$$
\begin{aligned}
& -\int_{i}^{j} \delta u d s \text {. }
\end{aligned}
$$

Assuming the two sources are so close that the rays of the wave are nearly the same and cancel each other out, equation 3 can be simplified to:

$$
r_{k}^{i}-r_{k}^{j}=\sum_{l=1}^{3} \frac{\partial \tau^{j} k}{\partial x^{i}} \Delta x+\Delta \tau^{i}-\sum_{l=1}^{3} \frac{\partial T^{j}}{\partial x^{j}} \Delta x x_{l}^{j}-\Delta \tau^{j}
$$

where $r_{k}^{i}-r_{k}^{j}$ is a double-difference (Waldhauser and Ellsworth, 2000). Double - difference is the time difference between observation data and calculated data between two adjacent earthquake sources which can be written as:

$$
r_{k}^{i}-r_{k}^{j}=\left(T^{i}-T_{k}^{j}\right)_{k}^{o b s}-\left(T^{i}-T^{j}\right)_{k}^{k a l k u l a s i}
$$

The difference in arrival time $\left(T_{k}^{i}-T^{j}\right)_{k}^{o b s}$ can be obtained by cross-correlation of the waveform or from the absolute time difference of the earthquake catalog data. Zhang and Thurber (2005) developed the TomoDD code based on the HypoDD code developed by Waldhauser (2001). Equation 3 can be applied to iterations and written in matrix form as: 


\section{FINDING AND DISCUSSION}

The DD method uses relative arrival times (cross-correlation data or differential catalog data) as well as absolute data to simultaneously relocate earthquakes and calculate 3D velocity models. Figure 2 is a histogram of the residual travel time in data subset 1 . The distribution of residuals before being relocated is in the range of $-3 \mathrm{~ms}$ to $2 \mathrm{~ms}$. The histogram of relocation shows a better distribution value than before being relocated with a value range of $-2 \mathrm{~ms}$ to $2 \mathrm{~ms}$. The residual travel time is calculated relative to the model used. The results of the relocation on the histogram which show a high frequency close to zero (0) statistically indicate that the relocation has a good accuracy of the results.
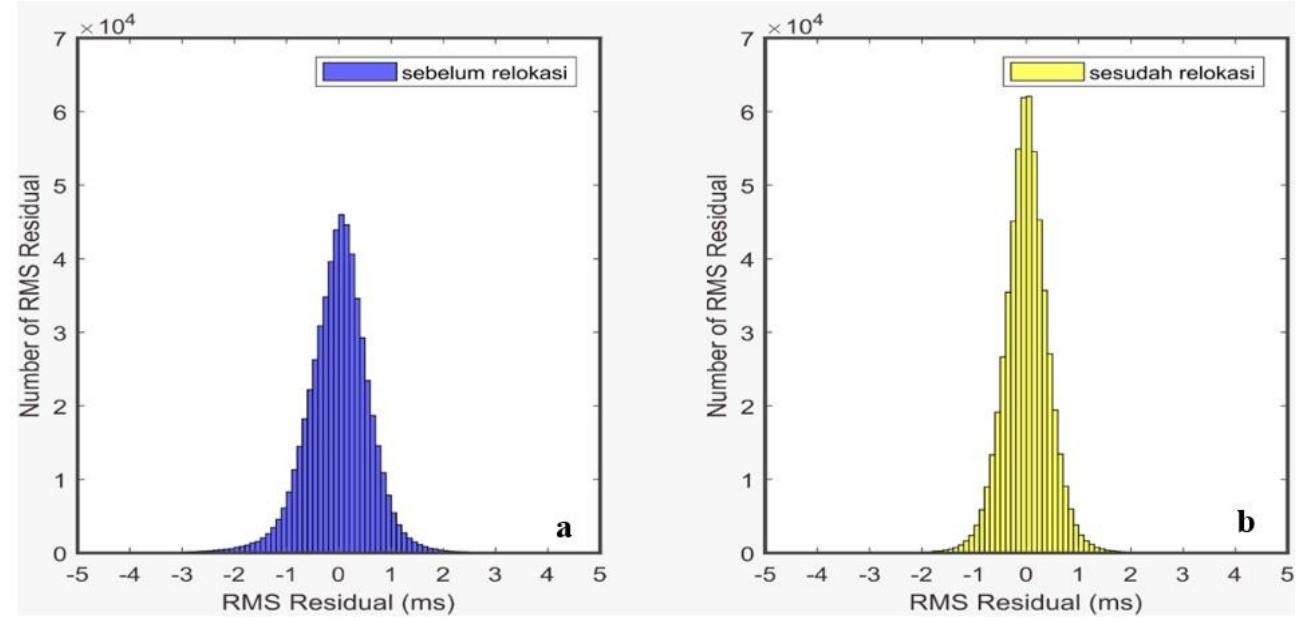

Figure 2. a) Histogram of the earthquake before being relocated, b) Histogram of the earthquake after being relocated

The distribution of earthquake relocation and the dominant direction of its distribution depends on the data used. The shift vector before and after being relocated is shown in Figure 3a. The relocation results show a shift from 0.5 meters to 150 meters (Figure $3 \mathrm{~b}$ ). The distribution before and after relocation in subset 1 is shown by a rosette diagram (Figure 4). Figure 4 shows the distribution of data before and after being relocated in all directions with the dominant direction being NE - SW. The distribution of events before and after relocation can be seen in Figure 5. The green dot is the distribution of all earthquake events before being relocated, while the blue color in the event that has been relocated, while the observation station is indicated by a red triangle (Figure 5).

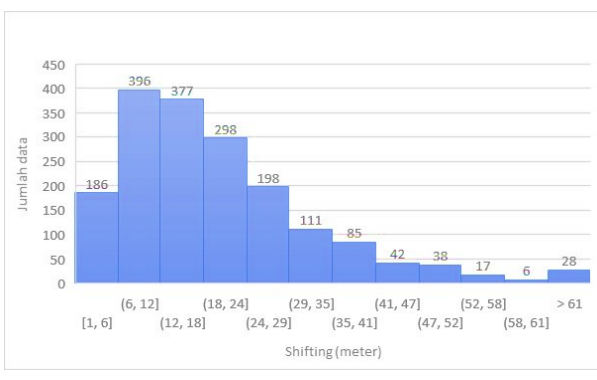

a

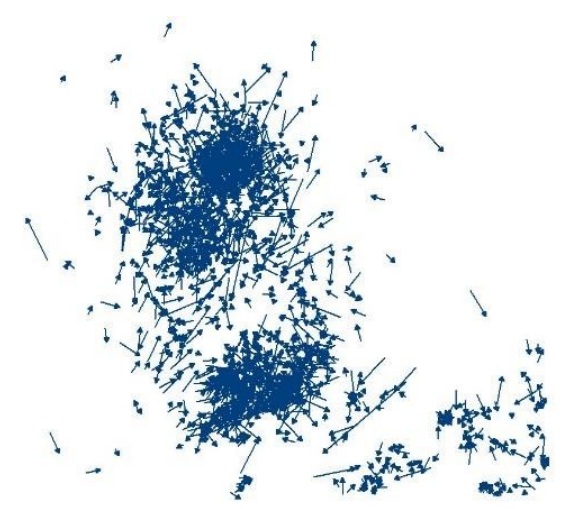

$\mathrm{b}$

Figure 3. a) Histogram and (b) Vector shifting before and after being relocated to the data 


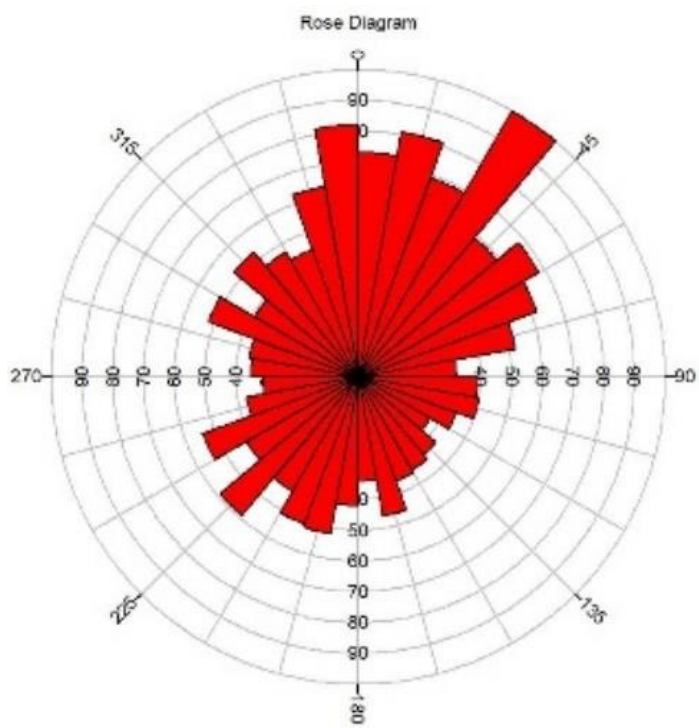

Figure 4. Rose diagram relocation

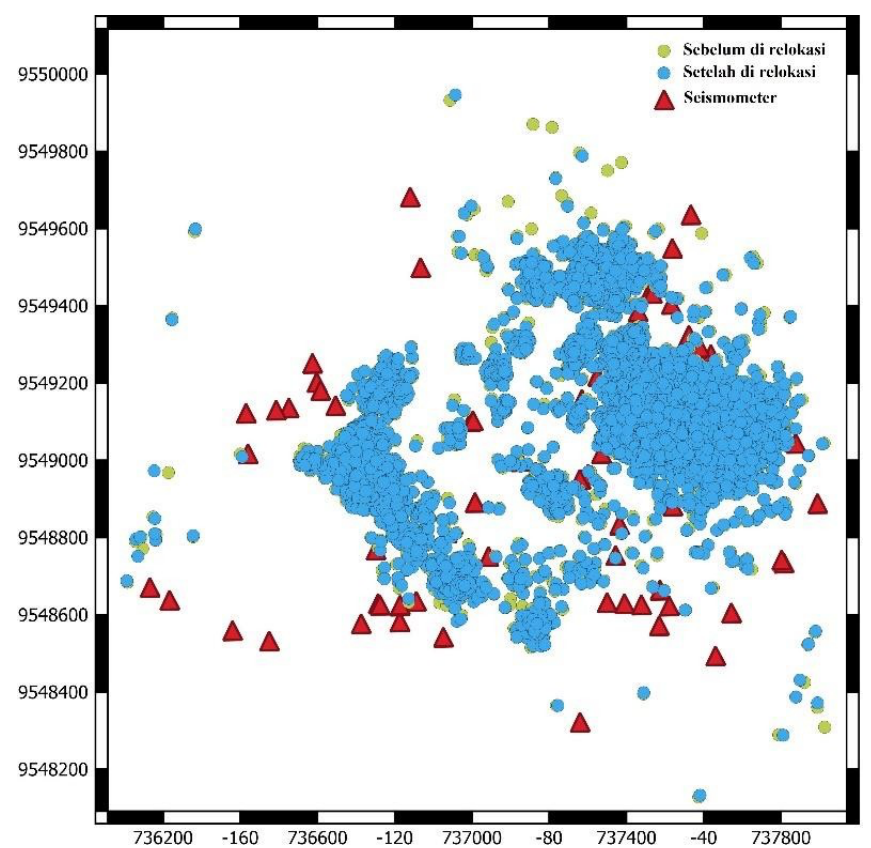

Figure 5. Location and relocation hypocenter (green dots are distribution of location microseismic events, b. distribution of microseismic events after being relocated)

\section{CONCLUSION AND FURTHER RESEARCH}

The results of the microseismic relocation in the study area are well covered, as evidenced by the residual histogram and shift distribution. The shift of the microseismic before and after being relocated spread in all directions with the dominant direction in the NE - SW direction. The value of the microseismic shift before and after being relocated ranged from 0.5 meters to 150 meters.

\section{REFERENCES}

Gibowicz and Lasocki. (2001). Seismicity Induced By Mining Ten Years Later. Advances in geophysics, vol. 44

Hidayat W., dan Haryanto, W. (2015): Analisa Potensi Spill Out Menggunakan Metode Resistivity Pada Area Panel 3 North Tambang Bawah Tanah Kabupaten Mimika Provinsi Papua. Prosiding seminar kebumian Ke-10. 
RSF Conference Series: Engineering and Technology

Vol 1 (1), 394-398

Earthquake Relocation Studies near Local Scale Sources using Double-Difference Technique

Wrego Seno Giamboro, Hafiz Hamdalah

$\mathrm{Ma}, \mathrm{Xu} \&$ Westman, Erik \& Counter, Dave \& Malek, Farid \& Slaker, Brent. (2020). Passive Seismic Imaging of Stress Evolution with Mining-Induced Seismicity at Hard-Rock Deep Mines. Rock Mechanics and Rock Engineering. 10.1007/s00603-020-02076-5.

Mendecki and Sciocatti (1997). Seismic Monitoring on Mines. Chapman and Hall. London

Waldhauser, F. (2001:: HypoDD: A Computer Program to Compute Double-difference Earthquake

Waldhauser, F., and Ellsworth, W.L. (2000): A Double-Difference Earthquake LocationAlgorithm: Method and Application to the Northern Hayward Fault, California. Bulletin of the Seismological Society of America 90, 1353-1368. https://doi.org/10.1785/0120000006

Zhang, H.J., and Thurber, C. (2005): Adaptive mesh seismic tomography based on tetrahedral and Voronoi diagrams: Application to Parkfield, California. J. Geophys. Res. 110 (B4), 225-243 